\title{
Relationship between Photomorphogenesis and Tree Growth in Cryptomeria japonica Assessed Using Light Emitting Diodes
}

\begin{abstract}
Haruna Kobayashi and Yohei Kurata *
Recently, there has been considerable interest in establishing tree-rearing methods for breeding nursery trees, which are similar to the methods employed in plant factories to produce vegetables. Studies have shown that the efficiency of tree cultivation can be improved by changing the wavelength of the lighting that is used to raise young plants and that light emitting diodes (LEDs) are effective for this purpose. In this study, the effect of blue $(450 \mathrm{~nm})$, red $(660 \mathrm{~nm})$, and white (combination of blue and yellow $(525 \mathrm{~nm})$ LED lights was investigated for rearing Cryptomeria japonica saplings. 7 saplings with each LED were prepared and reared for 52 weeks in a constant environment chamber (Temperature: $23 \pm 2{ }^{\circ} \mathrm{C}$, relative humidity $50 \% \pm 10 \%$ ), and their growth rates and root system morphology were compared. After 52 weeks of breeding, red light induced slightly more stem growth than white light. Blue light was nearly three times more effective in stem growth than white light. Furthermore, the wavelength of light affected the root system morphology. Many root branches were observed in saplings reared under red light, while marked taproot growth was observed in saplings reared under blue light. There was a possibility that saplings could be produced more efficiently by using LED.
\end{abstract}

DOI: 10.15376/biores.17.1.1136-1143

Keywords: Light emitting diode; Tree morphology; Root elongation; Root system morphology;

Cryptomeria japonica

Contact information: College of Bioresource Sciences, Nihon University, 1866 Kameino, Fujisawa, Kanagawa 252-0880, Japan; *Corresponding author: kurata.youhei@nihon-u.ac.jp

\section{INTRODUCTION}

Light absorption by plant leaves differs, depending on the wavelength of the incident light (Terashima et al. 2009). Growing plants only undergo photomorphogenesis at specific light wavelengths, and the relationship between the wavelength of incident light and photomorphogenesis has been widely studied (Kim et al. 2004; Kwon et al. 2015). In previous studies on the effect of light wavelength on plant growth, combinations of red and blue light have been used to promote the growth rate of plants (Brown et al. 1995; Hogewoning et al. 2010). Most of these studies examined plant photomorphogenesis in Arabidopsis thaliana or vegetables (e.g., leaf lettuce), and assessed how it could be applied to decrease the cultivation period and produce alternate generations (Nemhauser and Chory 2002; Johkan et al. 2010; Olle and Viršile 2013). However, relatively few studies have been conducted on photomorphogenesis in forestry species, which is likely because of the long rearing periods associated with trees.

It usually takes several years to grow tree saplings in outside environments. Rearing 
the saplings in a greenhouse decreases the length of their nursery period because of fewer insects and pathogenic bacteria and fungi. Furthermore, growing seedlings in containers (container seedlings) has been shown to facilitate tree establishment (South et al. 2004; Pinto et al. 2011a,b). The container seedlings method was introduced by forestry managers in Japan to minimize planting costs. In 2019, approximately 65 million seedlings were reared for planting, and of these, approximately 30\% were container seedlings (Forestry Agency Ministry of Agriculture, Forestry and Fisheries, Japan 2020). As the demand for container seedlings increases, methods for producing seedlings more efficiently will be needed in a greenhouse. Therefore, the use of light-emitting diodes (LEDs) as light sources for developing saplings in similar to plant factories could potentially be applied as a means to rear saplings more efficiently, particularly over the long term. LEDs have a potential for use long-term breeding because of low power consumption and longevity. Thus, in this study, long-term observations (52 weeks) were conducted in Cryptomeria japonica (Japanese cedar). Specifically, changes in tree height and root morphology were examined under red, blue, and white commercially available LED illuminations. If the nursery trees could be bred efficiently with LED, then larger trees could be bred at the time of planting in the plantation area. Large nursery trees have an advantage in terms of light acquisition.

\section{EXPERIMENTAL}

\section{Plant Rearing under LED Lights}

Three rearing chambers such as the one shown in Fig. 1 were prepared for each LED light treatment.

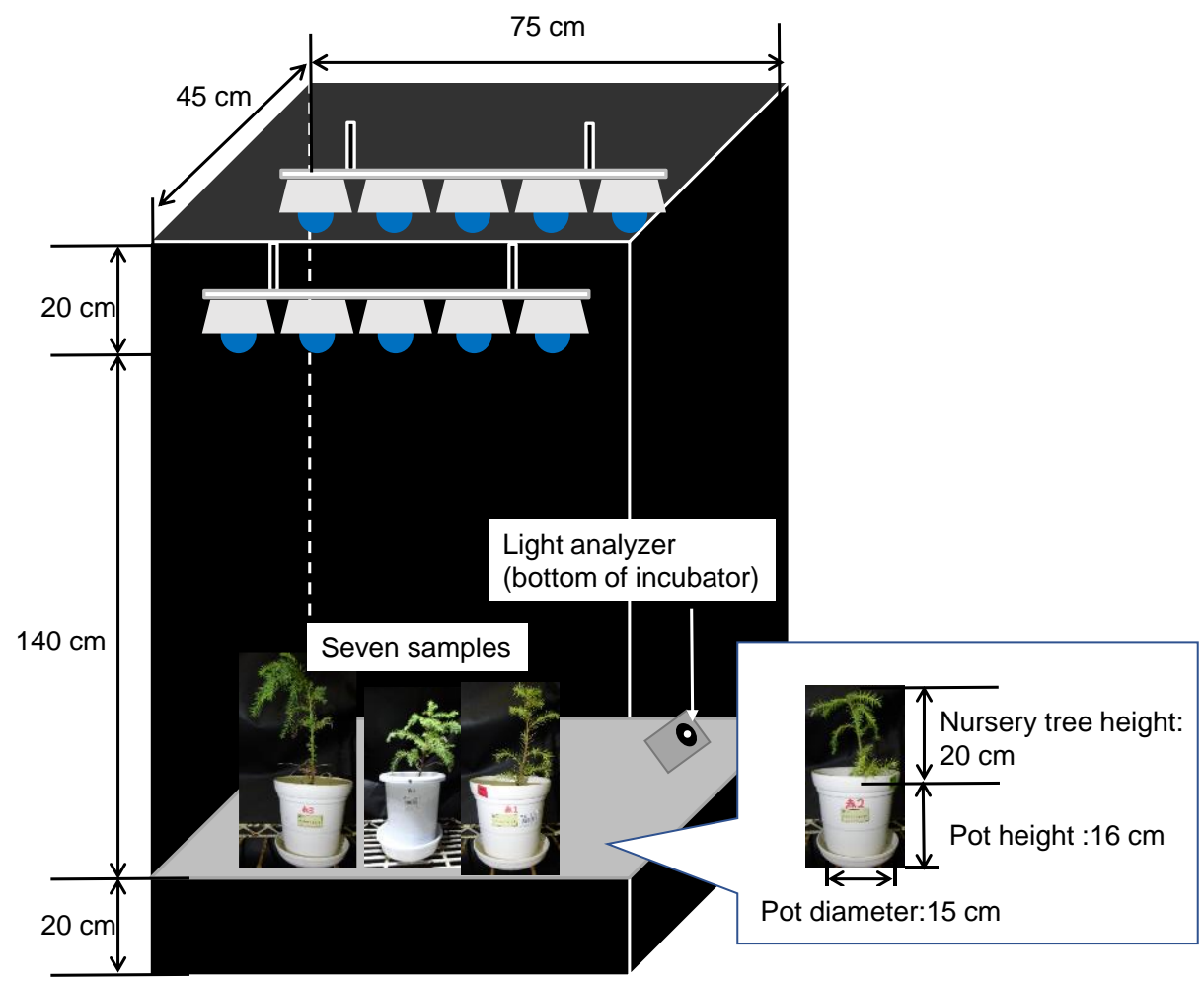

Fig. 1. Outline of growth chamber and light emitting diode system (blue light as example). The photosynthetic photon flux density was measured using a light analyzer placed at the bottom of the rearing chamber. 
The size of the pot was $15 \mathrm{~cm}$ in diameter and $16 \mathrm{~cm}$ in height, and each was filled with 1.0 L of soil amended with fertilizer (Metro-Mix 360, Hyponex, Tokyo, Japan). The temperature and relative humidity rearing chambers were maintained at $23{ }^{\circ} \mathrm{C} \pm 2{ }^{\circ} \mathrm{C}$ and $50 \% \pm 10 \%$, respectively. Water was supplied once a week to the extent that the ground was moist.

In each treatment, 7 Cryptomeria japonica saplings (about $20 \mathrm{~cm}$ tall from the ground surface) acquired from a commercial store were prepared. Saplings were rooted outside and bred with outside condition for about 18 month as nursery trees. The samples bred in white LED chamber were named W1 to W7. Similarly, the labels B1 to B7 were used to designate a blue LED chamber and R1 to R7 for a red LED chamber. The minimum distance between the center of saplings was $20 \mathrm{~cm}$. No individual sapling had developed enough leaves to cover other sapling after 52 weeks breeding. Cryptomeria japonica species was used because it is produced in large quantities in Japan, primarily for use as timber. The sample size from the ground surface in the pot to the apex of the sapling was measured once in every 4 weeks. The rearing period was 52 weeks during which time apical dominance was maintained.

\section{Light Source Characteristics of LEDs}

The LED lamps were used as light sources in this study: White LED (Tornado ACE-E26-3X1W-DW, Keystone Technology, Tokyo, Japan), red LED (Tornado ACEE26-3X1W-R, Keystone Technology), and blue LED (Tornado ACE-E26-3X1W-B, Keystone Technology). Power consumption per LED was 3 watts. Light from the outside was blocked by using the blackout curtain in each chamber, and only LED light was emitted inside the blackout curtain. The light intensity inside the chamber was regulated according to the photosynthetic photon flux density (PPFD).

Yamamoto et al. (2014) suggested that the optimal light intensity for plant factory using LED illumination was in the range 150 to $200 \mu \mathrm{mol} \cdot \mathrm{m}^{-2} \cdot \mathrm{s}^{-1}$ in conversion to PPFD. The PPFD value at the top of the tree was adjusted so that it was approximately 200 $\mu \mathrm{mol} \cdot \mathrm{m}^{-2} \cdot \mathrm{s}^{-1}$, which is considered sufficient for photosynthesis. The detailed characteristics of the light was measured using a light analyzer (Light analyzer LA-105, Nippon Medical and Chemical Instruments Co., Osaka, Japan) placed at the bottom of the chamber and are summarized in Table 1.

Table 1. Summary of Light Source Characteristics

\begin{tabular}{|l|l|l|l|l|}
\hline & & \multicolumn{3}{|l|}{ Light color $\left(\mu \mathrm{mol} \cdot \mathrm{m}^{-2} \cdot \mathrm{s}^{-1}\right)$} \\
\hline Parameter & Wavelength $(\mathrm{nm})$ & White & Red & Blue \\
\hline PPFD & 400 to 700 & 23.2 & 23.4 & 23.0 \\
\hline Ultraviolet & 380 to 400 & 0.03 & 0.03 & 0.03 \\
\hline Blue & 400 to 500 & 7.3 & 0.1 & 22.6 \\
\hline Green & 500 to 600 & 10.4 & 0.5 & 0.3 \\
\hline Red & 600 to 700 & 5.5 & 22.8 & 0.1 \\
\hline
\end{tabular}

PPFD: Photosynthetic photon flux density

The PPFD values measured at the chamber bottom for the three light sources were $23.2,23.0$, and $23.4 \mu \mathrm{mol} \cdot \mathrm{m}^{-2} \cdot \mathrm{s}^{-1}$ for the white, blue, and red LED lights, respectively. Figure 2 shows the relationship between the light irradiance and the wavelength of the three LED lights. The peaks obtained for the blue, red, were $450 \mathrm{~nm}, 660 \mathrm{~nm}$, respectively. White light consisted of a combination of blue and yellow lights $(525 \mathrm{~nm})$ (Tamoi et al. 2017). 
LED lights was continuously irradiated for $24 \mathrm{~h}$ every day.

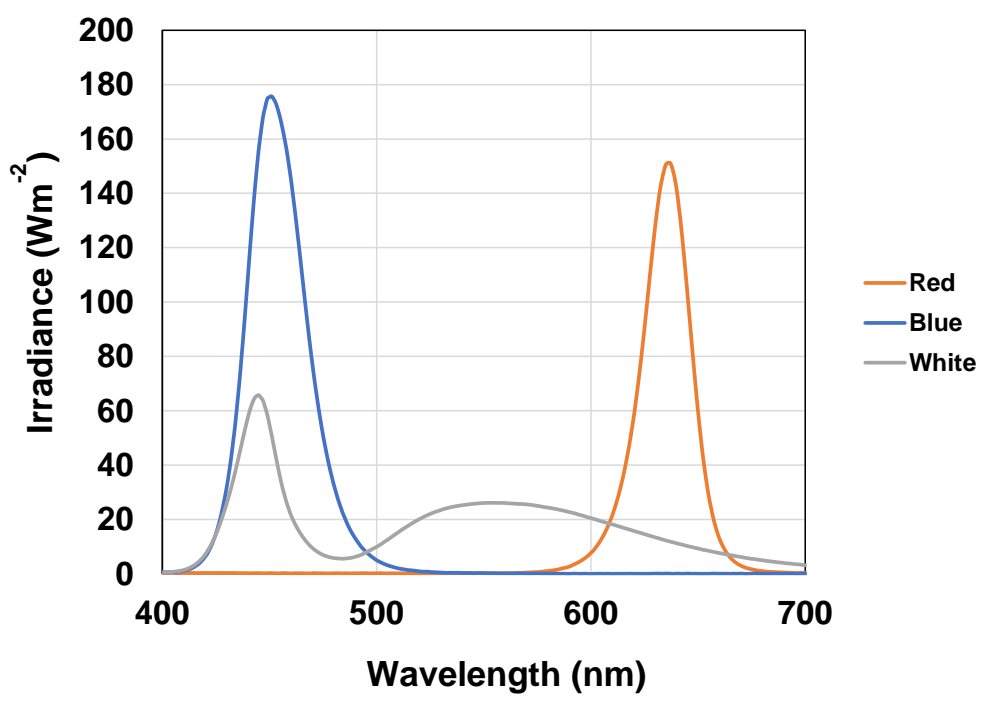

Fig. 2. Relationship between LED irradiances and wavelengths

\section{RESULTS AND DISCUSSION}

\section{Effect of LED Irradiance on Photomorphogenesis and Sapling Growth Rate}

Figure 3 shows the growth rates for the individual saplings reared under each type of LED illumination. All saplings exhibited growth, especially those irradiated with blue light. Figure 4 shows the average rate of sapling growth, with "zero" indicating the start of the experiment. The growth rate for saplings under red light was slightly higher than that under white light, while that for the saplings under blue light was nearly three times larger than that under white light. Thus, growth rates were fastest under blue light, followed by red and white light.

Table 2. Average Growth Rates for Saplings Used in this Study

\begin{tabular}{|c|c|c|c|c|c|c|}
\hline & \multicolumn{2}{|c|}{ White LED $(n=7)$} & \multicolumn{2}{|c|}{ Blue LED $(\mathrm{n}=7)$} & \multicolumn{2}{|c|}{$\operatorname{Red} \operatorname{LED}(\mathrm{n}=7)$} \\
\hline Week & $\begin{array}{c}\text { Average } \\
\text { Tree Growth } \\
\text { (cm) }\end{array}$ & $\begin{array}{l}\text { Standard } \\
\text { Deviation }\end{array}$ & $\begin{array}{c}\text { Average } \\
\text { Tree Growth } \\
\text { (cm) }\end{array}$ & $\begin{array}{l}\text { Standard } \\
\text { Deviation }\end{array}$ & $\begin{array}{c}\text { Average } \\
\text { Tree Growth } \\
\text { (cm) }\end{array}$ & $\begin{array}{l}\text { Standard } \\
\text { Deviation }\end{array}$ \\
\hline 0 & 0 & 0 & 0 & 0 & 0 & 0 \\
\hline 4 & 0.61 & 0.35 & 0.66 & 0.33 & 0.41 & 0.17 \\
\hline 8 & 0.99 & 0.44 & 2.16 & 1.61 & 0.84 & 0.67 \\
\hline 12 & 1.09 & 0.52 & 3.37 & 2.64 & 1.34 & 1.23 \\
\hline 16 & 1.29 & 0.58 & 4.44 & 3.07 & 1.74 & 1.62 \\
\hline 20 & 1.40 & 0.71 & 5.19 & 3.57 & 1.81 & 1.71 \\
\hline 24 & 1.47 & 0.70 & 5.50 & 3.80 & 1.86 & 1.76 \\
\hline 28 & 1.56 & 0.65 & 5.90 & 3.97 & 1.89 & 1.74 \\
\hline 32 & 1.59 & 0.66 & 6.10 & 4.04 & 1.89 & 1.74 \\
\hline 36 & 1.64 & 0.74 & 6.16 & 4.01 & 1.91 & 1.79 \\
\hline 40 & 1.66 & 0.73 & 6.27 & 4.13 & 1.93 & 1.78 \\
\hline 44 & 1.69 & 0.72 & 6.30 & 4.16 & 1.94 & 1.77 \\
\hline 48 & 1.73 & 0.72 & 6.39 & 4.10 & 2.00 & 1.79 \\
\hline 52 & 1.77 & 0.76 & 6.46 & 4.13 & 2.09 & 1.86 \\
\hline
\end{tabular}


Table 2 shows the average rates of tree growth and the standard variations. No difference in sapling height was observed at one month. Tree elongation was observed from the second month. The large standard deviation observed for saplings in the blue light treatment indicates that there was a large variation among individual saplings.
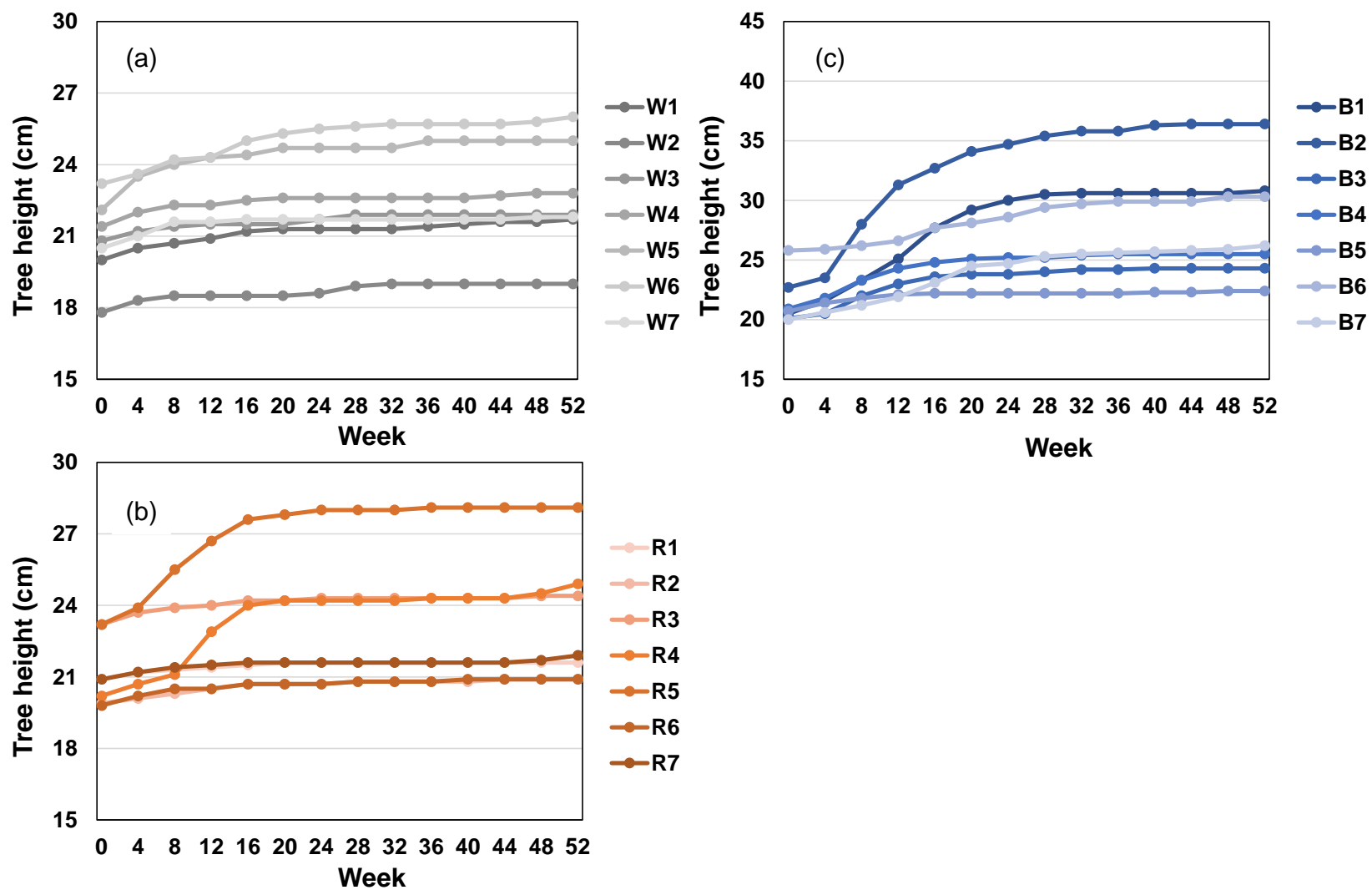

Fig. 3. Variations in individual sapling height over the course of the study under irradiance by (a) white LED; (b) red LED; and (c) blue LED lights. W1-W7, R1-R7, and B1-B7 indicate the seven individuals reared under white, red, and blue LED lights, respectively.

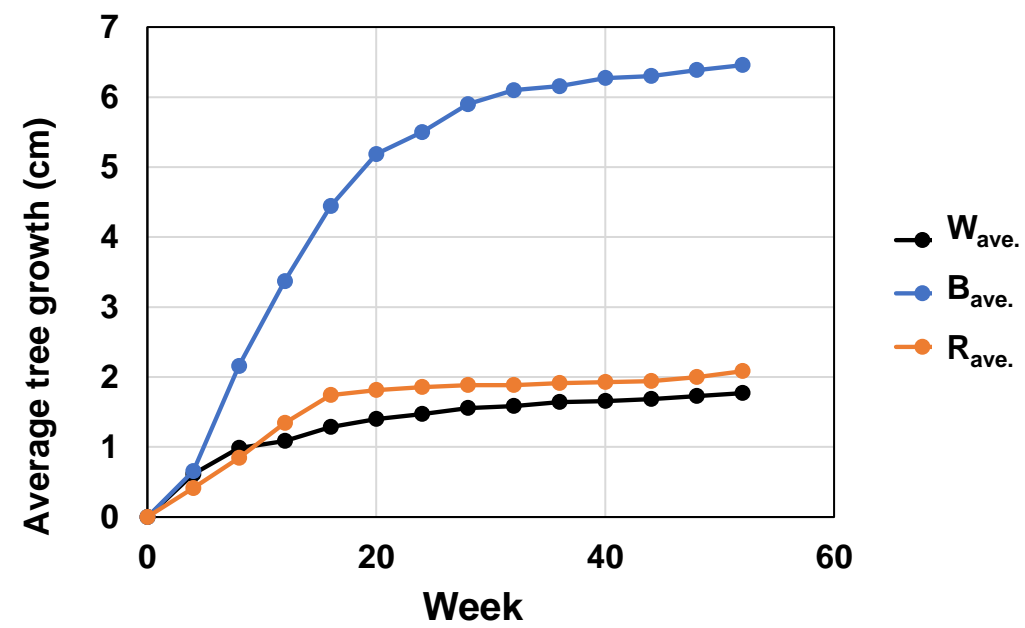

Fig. 4. Comparison of average growth rates obtained for saplings reared under white (black line), blue (blue line), and red (red line) LED lights 


\section{Differences in Root Morphogenesis}

Figure 5 shows the morphological differences in root system observed in saplings reared under each LED light treatment; (a) roots intact and (b) roots spread. The highest sapling was selected from each LED chamber. The leaf color of saplings reared under red light was a light yellow-green, and it was not as green as the leaves of saplings grown under white light. White LED was made by enclosing a yellow fluorescent substance in a blue LED in Fig. 2. Therefore, saplings with white LED were similar to blue LED in terms of leaf color.

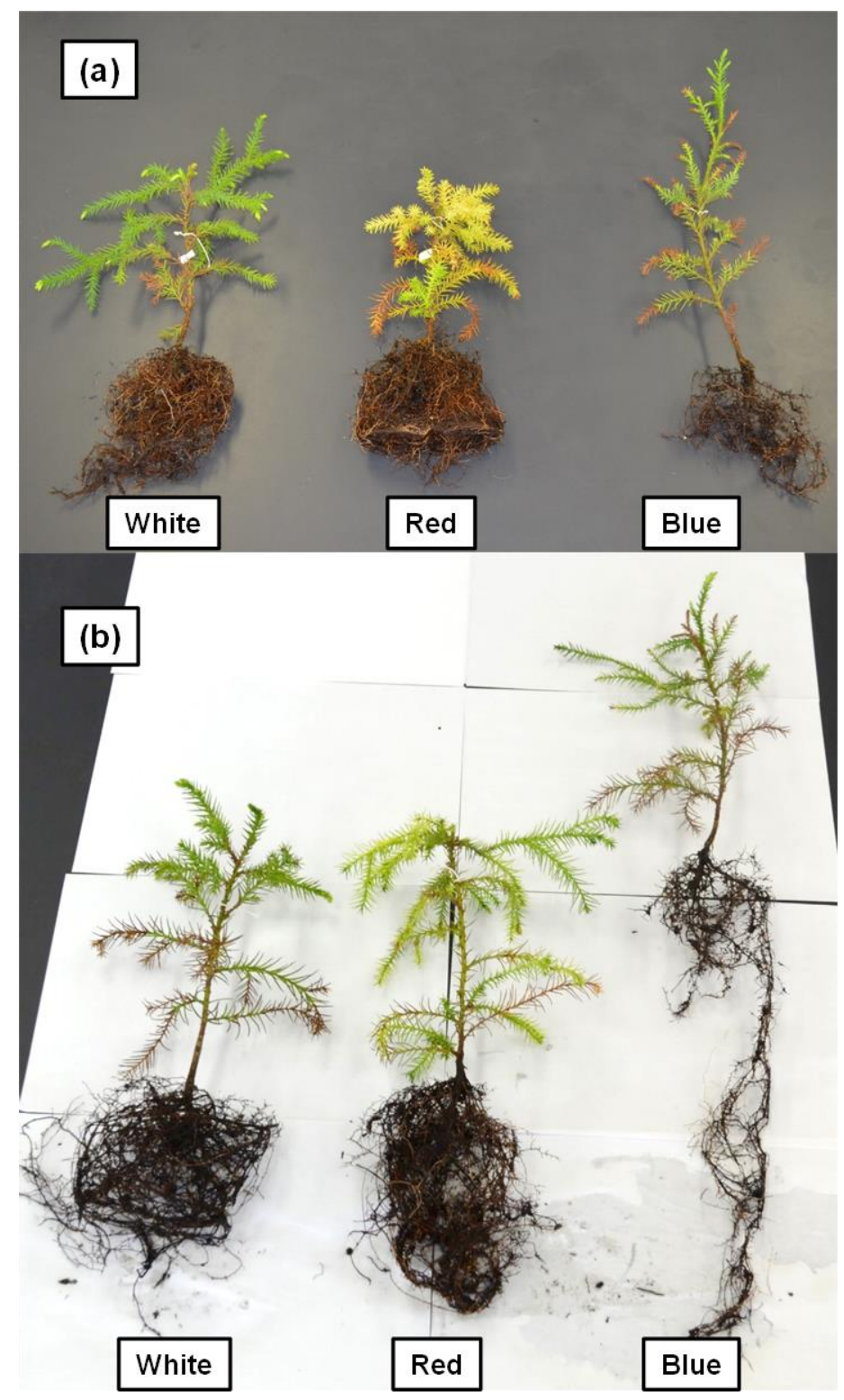

Fig. 5. Differences in root structures following cultivation with each LED lights: (a) Intact; and (b) root spread.

Changes in root morphogenesis were observed in saplings reared under the different wavelengths. Many root branches were observed in saplings reared under red light, while marked taproot growth was observed in saplings reared under blue light. A comparison of saplings reared under red and blue lights showed that those reared under blue light showed 
the most developed above ground growth and root length. There was the morphology difference that could be visually confirmed by breeding for a long-term observation. The influence of plant hormones such as auxin might be considered, but it could not be clarified in this study.

\section{CONCLUSIONS}

1. Long-term rearing of Cryptomeria japonica species was carried out using saplings reared under various light-emitting diode (LED) light wavelengths. The growth rate for saplings under red light was slightly higher than that under white light, while that for the saplings under blue light was nearly three times larger than that under white light. Tree height was thus considered to be well suited as an index if measured while maintaining apical dominance.

2. The best sapling growth was observed under blue light. Furthermore, changes in root growth and morphology were also observed under red and blue light. Differences in root morphogenesis also affect the stability of trees in the ground, which is an important consideration given the incidence of landslides in forested areas.

3. Sapling technology using LED was less advanced than plant or vegetable factories. However, if breeding could be done using LED illumination, there is a possibility that seedlings could be produced more efficiently than with conventional outdoor breeding. This research on breeding trees for a longer period than plants and vegetables gave key points to future LED seedling production technology.

\section{REFERENCES CITED}

Brown, S. C., Schuerger, C. A., and Sager, C. J. (1995). "Growth and photomorphogenesis of pepper plants under red light-emitting diodes with supplemental blue or far-red lighting," Journal of the American Society for Horticultural Science 120(5), 808-813. DOI: 10.21273/JASHS.120.5.808

Forestry Agency Ministry of Agriculture, Forestry and Fisheries, Japan. (2020). "Annual report on forest and forestry in Japan fiscal year 2020 (Summary)," Available online: https://www.rinya.maff.go.jp/j/kikaku/hakusyo/R2hakusyo/attach/pdf/index-1.pdf

Hogewoning, W. S., Trouwborst, G., Maljaars, H., Poorter, H., Ieperen, W., and Harbinson, J. (2010). "Blue light dose-responses of leaf photosynthesis, morphology, and chemical composition of Cucumis sativus grown under different combinations of red and blue light," Journal of Experimental Botany 61(11), 3107-3117. DOI: 10.1093/jxb/erq132

Johkan, M., Shoji, K., Goto, F., Hashida, S., and Yoshihara, T. (2010). "Blue lightemitting diode light irradiation of seedlings improves seedling quality and growth after transplanting in red leaf lettuce," HortScience 45(12), 1809-1814. DOI: 10.21273/HORTSCI.45.12.1809

Kim, H.-H., Goins, G. D., Wheeler, R. M., and Sager, J. C. (2004). “Green light supplementation for enhanced lettuce growth under red and blue light emitting diodes," HortScience 39, 1617-1622. DOI: 10.21273/HORTSCI.39.7.1617

Kwon, A.-R., Cui, H.-Y., Lee, H., Shin, H., Kang, K.-S., and Park, S.-Y. (2015). "Light 
quality affects shoot regeneration, cell division, and wood formation in elite clones of Populus euramericana," Acta Physiologiae Plantarum 37(65). DOI: 10.1007/s11738015-1812-0

Nemhauser, J., and Chory, J. (2002). "Photomorphogenesis," in: American Society of Plant Biologists, Arabidopsis Book. 1: e0054. DOI: e0054. 10.1199/tab.0054

Olle, M., and Viršile, A. (2013) "The effects of light-emitting diode lighting on greenhouse plant growth and quality," A gricultural and Food Science 22(2), 223-234. DOI: $10.23986 /$ afsci.7897

Pinto, R. J., Dumroese, K. R., Davis, S. A., and Landis, D. T. (2011a). "Conducting seedling stocktype trials: A new approach to an old question," Journal of Forestry 109(5), 293-299. DOI: 10.1093/jof/109.5.293

Pinto, R. J., Marshall, D. J., Dumroese, K. R., Davis, S. A., and Cobos, R. D. (2011b). "Establishment and growth of container seedlings for reforestation: A function of stocktype and edaphic conditions," Forest Ecology and Management 261, 1876-1884. DOI: 10.1016/j.foreco.2011.02.010

South, B. D., Harris, W. S., Barnett, P. J., Hainds, J. M., and Gjerstad, H. D. (2004). "Effect of container type and seedling size on survival and early height growth of Pinus palustris seedlings in Alabama, USA," Forest Ecology and Management 204(2), 385-398. DOI: 10.1016/j.foreco.2004.09.016

Tamoi, M., Ishida, K., Eguchi, M., Harada, K., Kijihana, I., and Shigeoka S. (2017). "Growth and photosynthetic characteristics of Arabidopsis and tobacco plants grown under LED lights PLANT FLEC," Journal of Science and High Technology in Agriculture 29(3), 96-103. DOI: 10.2525/shita.29.96

Terashima, I., Fujita, T., Inoue, T., Chow, S. W., and Oguchi, R. (2009). "Green light drives leaf photosynthesis more efficiently than red light in strong white light: Revisiting the enigmatic question of why leaves are green," Plant Cell Physiology 50(4), 684-697. DOI: 10.1093/pcp/pcp034

Yamamoto, H., Yoshikoshi, H., Iwaya, K., and Sonoyama, Y. (2014). "Vegetable production by light in plant factory," Journal of the Illuminating Engineering Institute of Japan 98(12), 630-634.

Article submitted: October 15, 2021; Peer review completed: December 5, 2021; Revised version received and accepted: December 17, 2021; Published: December 21, 2021. DOI: 10.15376/biores.17.1.1136-1143 